\title{
Quantifying the problem of kneeling after a two incision bone tendon bone arthroscopic anterior cruciate ligament reconstruction
}

\author{
Osman Riaz \\ Sohail Nisar \\ Hannah Phillips \\ Asim Siddiqui
}

Department of Orthopaedics and Trauma Surgery, Calderdale and Huddersfield Foundation NHS Trust, Huddersfield, UK

Corresponding author:

Osman Riaz

Department of Orthopaedics and Trauma Surgery, Calderdale and Huddersfield Foundation NHS Trust

Arce Street Lindley

HD3 3EA Huddersfield, UK

E-mail: osmanriaz@doctors.org.uk

\section{Summary}

Introduction: the aims of this study was to investigate the post-operative incidence of anterior knee pain and quantify the problem of kneeling in patients who have underwent anterior cruciate ligament $(A C L)$ reconstruction with a bone tendon bone (BTB) graft.

Methods: prospective study of 71 male patients who participated in competitive sports and underwent BTB ACL reconstruction using a two incision approach between August 2008 and May 2011. The patella defect was packed with bone graft, and the peritenon was preserved and repaired. A questionnaire was used to evaluate pain and kneeling capability. All patients had pre and post operative Lysholm/Tegner scores, KT1000 evaluation and hop tests to assess knee stability and function.

Results: 71 patients were operated and had a follow up of 42 months, mean age 29.8. 22 patients had anterior knee pain on kneeling, paraesthesia of anterior knee was found in 23 patients. 65 patients were still able to kneel and 6 found they were unable. 36 were able to kneel for unrestricted periods, 9 for 5-15 minutes, 15 kneel for 1-5 minutes and 5 for $>1$ minute. Anterior knee pain was compared to kneeling time $(P=0.001)$. Paraesthesia and kneeling time, $(P=0.001)$. Anterior knee pain when compared with Lysholm score $(P=0.540)$, hop test $(P=0.277)$, and Lachman's $(P=0.254)$.
Conclusions: two incision BTB grafting of the patella and repair of the paritenon minimises the length of scar at the front of the knee. This reduces any palpable defects which could be causation factor for pain whilst kneeling. We have quantified kneeling and pain, thus aiding patients and surgeons in making the right decision for graft choice for ACL reconstruction.

KEY WORDS: ACL, anterior knee pain, kneeling.

\section{Introduction}

Anterior knee pain and difficulty in kneeling are frequently quoted post-operative complications resulting in patient dissatisfaction following anterior cruciate ligament $(A C L)$ reconstruction using the patella tendon bone tendon bone autograft (BTB). There is a high incidence of anterior knee pain quoted in the literature of up to $60 \%$ associated with a single incision bone patellar tendon bone harvest for ACL reconstruction ${ }^{1}$. There are two main contributing factors resulting in anterior knee pain whilst kneeling following BTB ACL reconstruction. There is a reported incidence of up to $65 \%$ of injury to the infrapatellar branches of the saphenous nerve with a single vertical incision ${ }^{2}$. Histological changes at the donor site may also result in tendinopathy and subsequent pain on kneeling.

Other grafts have been used to reduce the donor site morbidity associated with the bone tendon bone graft $^{3}$. However it is widely accepted to have many advantages over other grafts choice with regards to mechanical strength, reliable fixation and faster incorporation with bone to bone healing and is a popular option for ACL reconstruction.

Several surgical techniques have been proposed to reduce the morbidity associated with $B T B$ harvesting such as suturing the peritenon to fill the donor site s,4 $^{3,4}$ and therefore reduce the likelihood of post-operative anterior knee pain. But according to Kartus et al. and Brandsson et al., these proposals do not diminish the incidence of anterior knee pain ${ }^{5,6}$.

A two incision mini-invasive approach for harvesting the patellar BTB graft has also been recommended, this allows harvest of the graft without tearing the peritenon and the majority of the neural branches. This prevents injury to the infrapatellar branches of the saphenous nerve and allows preservation of the peritenon which allows improved tendon healing process $^{7-9}$. 
The purpose of this study was to investigate the incidence of anterior knee pain and quantification of the true extent of the problem of kneeling following this procedure. The hypothesis of this study was that the incidence of anterior knee pain would be reduced using a two incision technique.

\section{Methods}

This was a prospective study of 71 male patients who underwent BTB ACL reconstruction between August 2008 and May 2011. All patients were operated by a single surgeon in district hospital setting. Inclusion criteria were male patients between the ages of 16 and 60 who undertook competitive sports including football, rugby and martial arts.

A two incision technique for harvesting the BTB graft was undertaken ${ }^{9}$. The graft harvest was obtained with the knee flexed at $90^{\circ} .2-2.5 \mathrm{~cm}$ incisions were made. The upper vertical incision was made on apex of the patella whilst the lower horizontal incision made on the anterior tibial tubercle (Fig. 1). The patellar bone block was $2 \mathrm{~cm}$ by $1 \mathrm{~cm}$ and an oscillating saw blade was used to harvest this. The peritenon layer was carefully separated using metzenbaum scissors and the patellar tendon was incised at the medial third at its insertion. The fibres were longitudinally split from the patella to the anterior tibial tubercle insertion. Forceps were used to pass between the peritenon and the tendon from tibial to patellar incision to gain extraction of the patella bone block through the tibial incision. A $2 \mathrm{~cm}$ tibial bone block was then cut using the oscillating saw. The BTB graft was consequently obtained via a two incision approach. An antero-lateral and antero-medical approach was used for arthroscopy and both tunnels were created independently. The femoral tunnel was drilled through the anteromedial portal as it gives the more freedom to anatomically place the tunnel in the real femoral ACL footprint. We believe patients have a functional outcome compared to transtibial drilling.

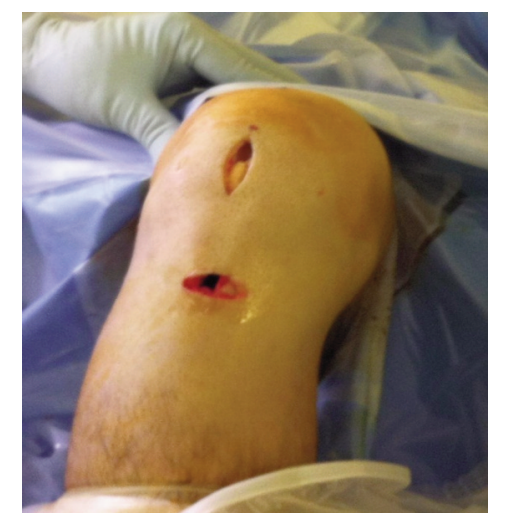

Figure 1. Location of incisions for BTB harvesting from patellar tendon.

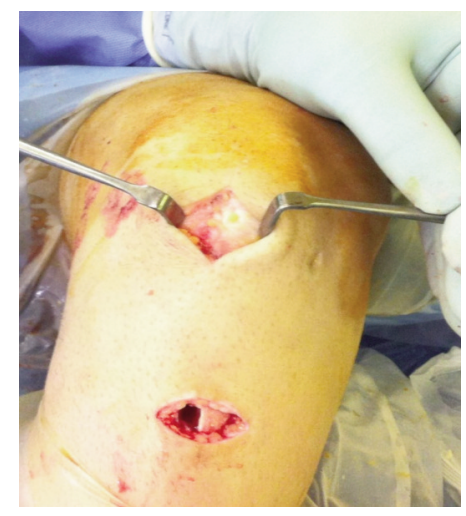

Figure 2. Donor site packed with bone graft obtained from drill reaming and peritenon repaired.

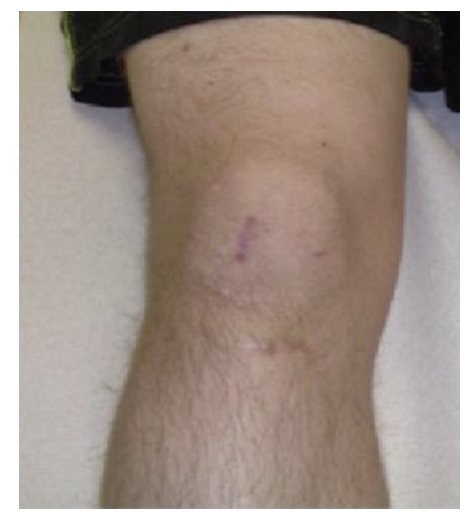

Figure 3. Cosmetic appearance of scars following 6 months follow up two mini-incision BTB harvesting.

The patella defect was packed with bone graft and the peritenon was preserved and repaired at the end of the procedure (Figs. 2,3). Bone grafts were taken from the reaming of the femoral and tibial drilling by saline irrigation and collected in a sterile side bag. The saline in the bag was then filtered to collect the bone graft.

A standardised questionnaire (Kujala Anterior Knee Pain Scale) was used to evaluate knee pain and addition questionnaire which we constructed were asked regarding kneeling capability. Each patient had a telephone interview for evaluation. Patients were also asked how much kneeling was involved in their occupation. The diagnosis of anterior knee pain was based on a direct question to the patient, "Is the front of your knee painful?" Thus pain severity was not deduced by the examiner. In all patients, pain, kneeling time and subjective hypoesthesia were recorded. All patients had pre and post-operative Tegner Lysholm knee scores, and KT1000 evaluation and hop tests to assess knee stability and function during clinic follow up. Data was collected on a graphic spreadsheet (Excel Microsoft $\left.{ }^{\circledR}\right)$. The level of significance was set at $5 \%$ and was calculated using a Mann Whitney test.

We Authors can confirm the ethics and conduct of our study complies with the international standards as described by this Journal ${ }^{10}$. 
Quantifying the problem of kneeling after a two incision bone tendon bone arthroscopic anterior cruciate ligament reconstruction

\section{Results}

71 male patients underwent BTB ACL reconstruction between August 2008 and May 2011. The follow up period was to 42 months. The age range was $16-50$ years with a mean age of 29.8 years $( \pm 2.06)$. The overall final patient follow up was $100 \%$.

Table 1 demonstrates the incidence of anterior knee pain whilst kneeling, paraesthesia, ability to kneel and return to pre-injury level of sports post-operatively. The incidence anterior knee pain was 22/71 (31\%) with a similar incidence of paraesthesia in $23 / 71$

Table 1. Incidence of anterior knee pain, paraesthesia, ability to kneel, and return to pre-injury level for two mini-incision BTB harvesting for ACL reconstruction.

\begin{tabular}{|c|c|c|}
\hline & Percentage & $\begin{array}{l}\text { No of } \\
\text { patients } \\
(\mathrm{N}=71)\end{array}$ \\
\hline \multicolumn{3}{|c|}{ Anterior Knee Pain } \\
\hline Yes & $31 \%$ & 22 \\
\hline No & $69 \%$ & 49 \\
\hline \multicolumn{3}{|c|}{ Paraesthesia } \\
\hline Yes & $32 \%$ & 23 \\
\hline No & $68 \%$ & 48 \\
\hline \multicolumn{3}{|c|}{ Ability to Knee } \\
\hline Yes & $92 \%$ & 65 \\
\hline No & $8 \%$ & 6 \\
\hline \multicolumn{3}{|c|}{ Return to pre-injury level } \\
\hline Yes & $78 \%$ & 55 \\
\hline No & $22 \%$ & 16 \\
\hline
\end{tabular}

(32\%). 65/71 (92\%) of the patients were still able to kneel. $55(78 \%)$ patients were able to return to their pre-injury level of physical activity.

Table 2 shows the mean pre-operative Lysholm score was $54.12 \pm 3.93(\mathrm{P}<0.05)$ and 6 months post-operatively was $94.14 \pm 1.46(\mathrm{P}<0.05)$. The mean Tegner score pre-operatively was $8.60 \pm 0.35(P<0.05)$ and post-op was $8.28 \pm 0.43(\mathrm{P}<0.05)$.

Figure 4 illustrates the kneeling time involved in the patients' occupations. 29/71 patients had occupations which involved kneeling time more than 10 minutes, $16 / 71$ had a kneeling time of less than 10 minutes and 26/71 patients' occupation did not involve kneeling. Figure 5 demonstrates the kneeling time in the 65 patients who could kneel. Of these 36/65 (51\%) patients were able to kneel for unrestricted periods, $9 / 65(13 \%)$ patients were able to kneel for a period of 5 to 15 minutes, $15 / 65$ (21\%) patients were able to kneel for 1 to 5 minutes and 5/65 (7\%) patients could kneel for less than 1 minute. 6/65 (8\%) patients were unable to kneel.

Table 3 demonstrates the relationship between paraesthesia reported by patient and kneeling time.

Table 2. Showing pre-op and post-op Lysholm and Tegner scores for two mini-incision BTB harvesting for $\mathrm{ACL}$ reconstruction.

\begin{tabular}{lll}
\hline & Pre-op & Post-op at 6 months \\
\hline Lysholm & $54.12 \pm 3.93(P<0.05)$ & $92.14 \pm 1.46(P<0.05)$ \\
Tegner & $8.60 \pm 0.35(P<0.05)$ & $8.28 \pm 0.43(P<0.05)$ \\
\hline
\end{tabular}
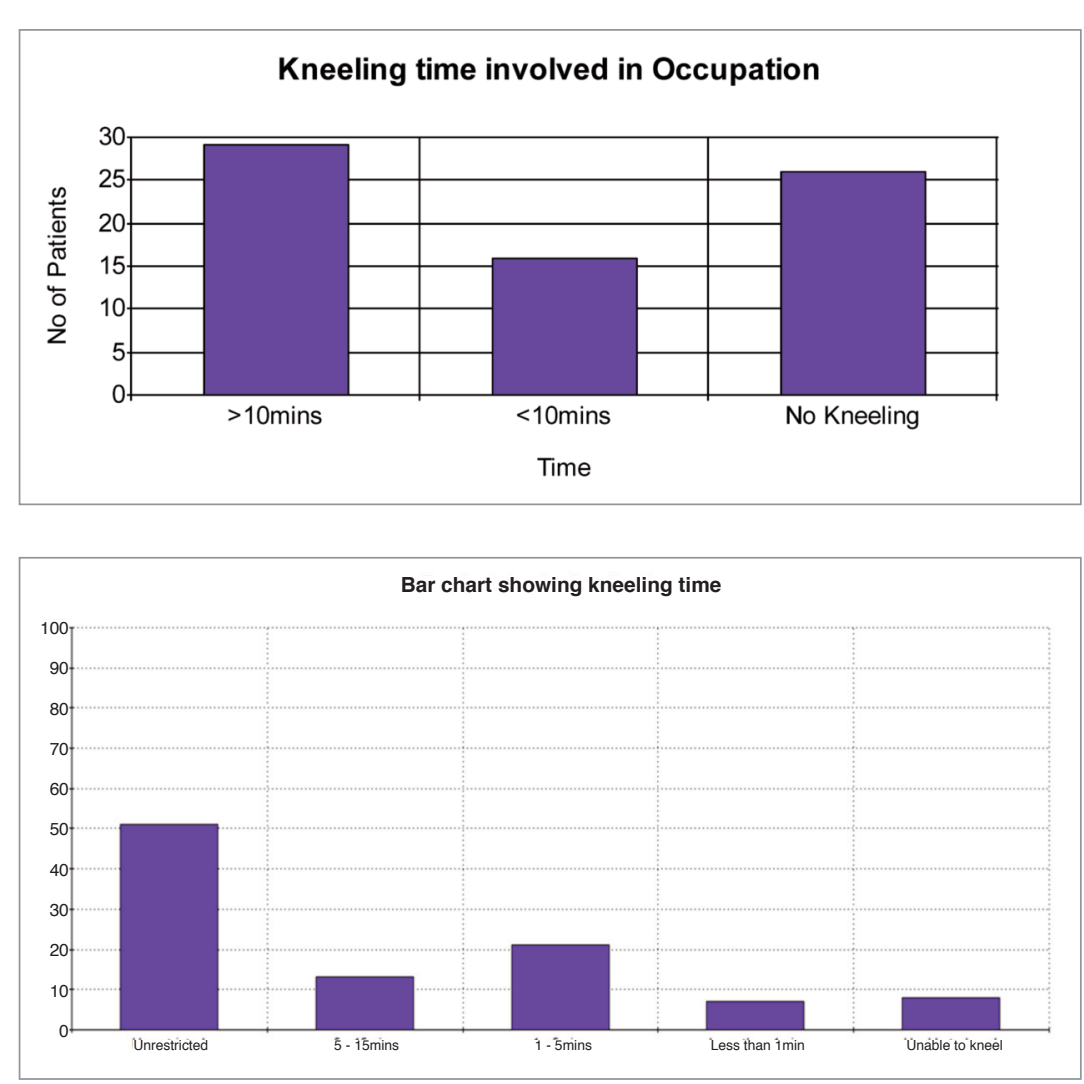

Figure 4. Kneeling time involved in occupation for our patient group.

Figure 5. Showing the kneeling time capability for our patients with two mini-incision $\mathrm{ACL}$ reconstruction. 
Table 3. Paraesthesia compared with kneeling time.

\begin{tabular}{llllll}
\hline Kneeling time & $\mathrm{N}$ & Mean & Lower Quartile & Upper Quartile & $P$ value \\
\hline Paraesthesia & & & & & \\
Yes & 23 & $1-5$ mins & $<1$ min & $5-15$ mins & $<0.001$ \\
No & 48 & Unrestricted & $1-5$ mins & Unrestricted & \\
\hline
\end{tabular}

Table 4. Anterior knee pain compared with functional outcome and kneeling time.

\begin{tabular}{|c|c|c|c|c|c|}
\hline Anterior knee pain & $\mathrm{N}$ & Mean & Lower Quartile & Upper Quartile & $P$ value \\
\hline \multicolumn{6}{|c|}{ Post-op Lysholm at 6 months } \\
\hline Yes & 22 & 94 & 85 & 96 & \multirow[t]{2}{*}{0.540} \\
\hline No & 49 & 91 & 85 & 95 & \\
\hline \multicolumn{6}{|c|}{ Hop test at 6 months } \\
\hline Yes & 22 & 95 & 90 & 100 & \multirow[t]{2}{*}{0.277} \\
\hline No & 49 & 100 & 90 & 100 & \\
\hline \multicolumn{6}{|c|}{ Lachman's test at 6 months } \\
\hline Yes & 22 & $<5 \mathrm{~cm}$ & $<5 \mathrm{~cm}$ & $<5 \mathrm{~cm}$ & \multirow[t]{2}{*}{0.254} \\
\hline No & 49 & $<5 \mathrm{~cm}$ & $<5 \mathrm{~cm}$ & $5-10 \mathrm{~cm}$ & \\
\hline \multicolumn{6}{|l|}{ Kneeling time } \\
\hline Yes & 22 & $1-5 \mathrm{mins}$ & $<1 \min$ & $5-15$ mins & \multirow[t]{2}{*}{0.001} \\
\hline No & 49 & Unrestricted & $1-5$ mins & Unrestricted & \\
\hline
\end{tabular}

Patients with paraesthesia had a statistical difference in overall kneeling time, with a mean of 1-5 minutes compared to patients who did not report paraesthesia had unrestricted ability to kneel.

In Table 4, we have looked at the association of reported anterior knee pain with Lysholm, hop test, Lachman's test and kneeling time. There is no significant difference when comparing anterior knee pain with Lysholm scores $(P=0.540)$, hop test $(P=0.277)$ and Lachman's $(P=0.254)$. However you can see anterior knee pain has a statistical association with the length of kneeling time $(P=0.001)$. For the patients who reported pain $(n=22)$, the mean kneeling time was 1-5 minutes and patients who did not report pain $(n=49)$, the mean kneeling time was unrestricted.

From the results we can conclude there is a statistical association between anterior knee pain and the inability to kneel, and the ability to kneel associated with paraesthesia. There was no correlation between Lysholm score, hop test and KT1000 scores with regards to ability to kneel.

\section{Discussion}

In our study, the incidence of anterior knee pain was lower than the single incision approach with a reported incidence of $40-60 \%{ }^{2}, 3,13-15$. In our series the incidence of anterior knee pain at follow up at 42 months was $31 \%$. However it was a direct question to the patients, and the examiner did not score the severity of pain, therefore a minor anterior discomfort may have been regarded as pain by the patient.

Anterior knee pain is likely to be related to patellar tendinopathy of the donor site or damage to the infrapatellar brances of the saphenous nerve. Anatomical studies have assessed the course of the saphenous nerve in the anterior knee area ${ }^{16,17}$. This highlights the probable risk of injury to this nerve when using the standard single incision approach to BTB harvesting resulting in paraesthesia or a painful neuroma. The results of our study showed a statistically significant difference between paraesthesia and kneeling capability. We believe our technique using a two incision approach reduces the chance of injury to these nerves, thereby reducing the incidence of anterior knee pain in comparison to a single incision approach.

Horizontal incisions and dissection of the retaniculum were advocated by Tsuda et al. ${ }^{11}$ in order to improve surgical access to the patellar tendon and the tibial tunnel and reduce the potential risk of injury to the neurological structures. Mishra et al. ${ }^{12}$ proposed that horizontal incisions would lead to a more satisfactory cosmetic appearance.

The published literature is not clear about the morbidity effects after grafting the ACL with BTB or semitendinosus graft (SG). Patellar tendon harvesting may result in damage of the infrapatellar nerves and giving donor site pain. However on the other hand, when SG grafts are harvested, a branch of the saphenous nerve might also be jeopardized ${ }^{18}$, probably at the stripping stage. Eriksson et al. ${ }^{19}$ reported that the area of disturbed sensitivity after either SG or BTB is comparable but with less clinical importance with SG. For Corry et al. ${ }^{20}$ and Spicer et al. ${ }^{21}$, SG grafts significantly reduce anterior knee symptoms and rarely cause limitation in activity when compared to BTB.

Knee extension deficiency can be an important predisposing factor for anterior knee pain especially early in post-operative period, this can be associated with impaired quadriceps function. Therefore early recovery of full extension may prevent anterior knee pain and achieve successful outcomes for ACL reconstruction. In the literature it has been agreed that the restoration of full extension compared with the non-injured side after $A C L$ reconstruction is essential to avoid post-operative anterior knee pain ${ }^{21,22}$. 
Quantifying the problem of kneeling after a two incision bone tendon bone arthroscopic anterior cruciate ligament reconstruction

In our study there was no correlation between Lysholm score, hop test, KT1000 and ability to kneel. This suggests that the Lysholm score may imply to clinicians that patients are doing well from an ACL reconstruction but does not indicate whether there are any issues that patients may have regarding kneeling and hence functional return to work. We believe patients should routinely undergo evaluation for kneeling ability as well as Lysholm, Hop and KT1000 tests to fully evaluate their functional outcome following BTB ACL reconstruction.

Our results for kneeling ability showed that $92 \%$ of our population were able to kneel and over $51 \%$ were able to kneel for unrestricted periods. This result highlights the problem of kneeling with regards to BTB harvest of the patella can be reduced by using our surgical approach.

\section{Limitations}

We acknowledge the limitations of our study. We did not objectively score anterior knee pain, it was a subjective answer from each patient, who may have regarded minimum discomfort as pain. A control group using a single incision may have strengthened our conclusions. Data on associated injuries and procedures were not collected. The questionnaire was specifically designed for this study and was not previously validated. Ideally, a clinical double-bind review and assessment of objective sensory loss would have been more reliable.

\section{Conclusions}

Two incision BTB harvest with bone grafting of patella defect and repair of the paritenon minimises the length of the scar at the front of the knee and also aims to reduce any palpable defects at the inferior pole of the patella which we feel could be causation factors of anterior knee pain especially on kneeling. The two incision approach reduces the incidence of anterior knee pain as well as the incidence of paraesthesia thus allowing a large proportion of patients to kneeling for unrestricted periods. Preservation of the infrapatellar branches of the saphenous nerve and better tendon trophicity through preservation of the peritenon thus provides strong evidence for efficiency and reliability of the two incision technique. Furthermore, this technique does not compromise the quality of reconstruction.

The BTB graft is often quoted as the gold standard and has many advantages over hamstring tendons with regards to strength, fixation and faster incorporation with bone to bone healing. Patients often want to know just how much of a problem they may have with regards to kneeling after this graft is used, and we have quantified the problem which should help answer these questions and aid patients and surgeons in making appropriate decisions when choosing the graft for ACL reconstruction.

\section{References}

1. Plancher KD, Steadman JR, Briggs KK, Hutton KS. Reconstruction of the anterior cruciate ligament in patients who are at least forty years old. A long-term follow-up and outcome study. J Bone Joint Surg Am. 1998;80:184-197.

2. Luo H, Yu JK, Ao YF. Relationship between different skin incisions and the injury of the infrapatellar branch of the saphenous nerve during anterior cruciate ligament reconstruction. Chin Med J (Engl). 2007;120:1127-1130.

3. Shaieb MD, Kan DM, Chang SK, Marumoto JM, Richardson AB. A prospective randomized comparison of patellar tendon versus semitendinosus and gracilis tendon autografts for anterior cruciate ligament reconstruction. Am J Sports Med. 2002; 30:214-220.

4. Liu SH, Hang DW, Gentili A, Finerman GA. MRI and morphology of the insertion of the patellar tendon after graft harvesting J Bone Joint Surg Br. 1996;78:823-826.

5. Berg P, Mjoberg B. A lateral skin incision reduces peripatellar dysaesthesia after knee surgery. J Bone Joint Surg Br. 1991; 73:374-376.

6. Kartus J, Movin T, Karlsson J. Donor-site morbidity and anterior knee problems after anterior cruciate ligament reconstruction using autografts. Arthroscopy. 2001;17:971-980.

7. Brandsson S, Faxen E, Eriksson BI, Kalebo P, Sward L, Lundin $\mathrm{O}$, et al. Closing patellar tendon defects after anterior cruciate ligament reconstruction: absence of any benefit. Knee Surg Sports Traumatol Arthroscopy. 1998;6:82-87.

8. Kartus J, Ejerhed L, Sernert N, Brandsson S, Karlsson J. Comparison of traditional and subcutaneous patellar tendon harvest. A prospective study of donor site-related problems after anterior cruciate ligament reconstruction using different graft harvesting techniques. Am J Sports Med. 2000; 28:328-335.

9. Tsuda E, Okamura $Y$, Ishibashi $Y$, Otsuka H, Toh S. Techniques for reducing anterior knee symptoms after anterior cruciate ligament reconstruction using a bone-patellar tendonbone autograft. Am J Sports Med. 2001;29:450-456.

10. Drain $\mathrm{O}$, Beaufils $\mathrm{P}$, Thevenin Lemoine $\mathrm{C}$, Boggione $\mathrm{C}$, Katabi $\mathrm{M}$, Charrois O. Mini invasive double incision for patellar tendon harvesting in anterior cruciate ligament reconstruction. Rev Chir Orthop. 2007;93:836-841.

11. Padulo J, Oliva F, Frizziero A, Maffulli N. Muscles, Ligaments and Tendons Journal. Basic principles and recommendations in clinical and field science. MLTJ. 2013; 4:250-252.

12. Tsuda E, Okamura $Y$, Ishibashi $Y$, Otsuka H, Toh S. Techniques for reducing anterior knee symptoms after anterior cruciate ligament reconstruction using a bone-patellar tendonbone autograft. Am J Sports Med. 2001;29:450-456.

13. Mishra AK, Fanton GS, Dillinham MF, Carver TJ. Patellar tendon graft harvesting using horizontal incisions for anterior cruciate ligament reconstruction. Arthroscopy. 1995;11:749-752.

14. Shaieb MD, Kan DM, Chang SK, Marumoto JM, Richardson $\mathrm{AB}$. A prospective randomized comparison of patellar tendon versus semitendinosus and gracilis tendon autografts for anterior cruciate ligament reconstruction. Am J Sports Med. 2003 30:214-220.

15. Otto D, Pinczewski LA, Clingeleffer A, Odell R. Five-year results of single-incision arthroscopic anterior cruciate ligament reconstruction with patellar tendon autograft. Am J Sports Med. 1998;26:181-188.

16. Ejerhed L, Kartus J, Sernert N, Kohler K, Karlsson J. Patellar tendon or semitendinosus tendon autografts for anterior cruciate ligament reconstruction? A prospective randomized study with a two-year follow-up. Am J Sports Med. 2003;31:19-25.

17. Arthornthurasook A, Gaew-Im K. Study of the infrapatellar nerve. Am J Sports Med. 1988;16:57-59.

18. Kartus J, Ejerhed L, Eriksson BI, Karlsson J. The localization of the infrapatellar nerves in the anterior knee region with special 
emphasis on central third patellar tendon harvest: a dissection study on cadaver and amputated specimens. Arthroscopy. 1999;15:577-586.

19. Brown $\mathrm{CH}$, Steiner ME, Carson $\mathrm{EW}$. The use of hamstring tendons for anterior cruciate ligament reconstruction. Technique and results. Clin Sports Med. 1993;12(4):723-756.

20. Eriksson K. On the semitendinosus in anterior cruciate ligament reconstructive surgery. Thesis Karolinska Institute Stockholm. 2001.
21. Corry IS, Webb LM, Clingeleffer AJ, Pinczewski LA. Arthroscopic reconstruction of the anterior cruciate ligament. A comparison of patellar tendon autograft and four-strand hamstring tendon autograft. Am J Sports Med. 1999;27(4):444-454.

22. Bertram C, Porsch M, Hackenbroch MH, Terhaag D. Saphenous neuralgia after arthroscopically assisted anterior cruciate ligament reconstruction with a semitendinosus and gracilis tendon graft - case report. Arthroscopy. 2000;16:763766. 